\title{
Histiocitosis de células Langerhans (Histiocitosis X), en el tracto genital femenino, presentación de tres casos y revisión de la literatura
}

\author{
Edgar Yesid Parra ${ }^{1}$; Lilia M. Sánchez B. ${ }^{2}$; Elvira Castro de Pabón ${ }^{3}$; Germán Barbosa ${ }^{4}$; Ariel Ruíz P.5; Miguel Aragón ${ }^{6}$
}

\section{RESUMEN}

El compromiso del tracto genital femenino por la Histiocitosis de células de Langerhans (HCL) muy raro, desde su descripción inicial se ha informado en la literatura casos individuales y series pequeñas. El compromiso a este nivel es variado, puede ser solitario vulvar, vaginal y/o cervical, o, concomitante con otras lesiones sistémicas, óseas o con diabetes insípida, este compromiso a determinado cuatro patrones de presentación clínica que han sido agrupados, igualmente se han establecido criterios de microscópica de luz, inmunohistoquímica y microscopia electrónica para el poder realizar el diagnostico definitivo de esta entidad. La historia natural de la HCL es impredecible, al igual que lo es la respuesta al tratamiento. Recientemente en el Instituto Materno Infantil (IMI) y el Instituto Nacional de Cancerología (INC) de Bogotá fueron diagnosticados tres casos nuevos, los cuales son la base de nuestra presentación y la revisión de la literatura.

PALABRAS CLAVES: Histiocitosis de células de Langerhans, Tracto genital femenino, Diabetes insípida.

\section{SUMMARY}

The Langerhans cell Histiocytosis of the female genital tract is rare. Since first described, few cases have been reported in the medical literature. In the female genital tract, the Langerhans cell histiocytosis $(\mathbf{L C H})$, can affect the vulva, vagina and the cérvix, alone, or can associate with other manifestations like Diabetes Insipid or bone lesions. This disease can present in 4 different clinical ways. Specific features have been identified with light microscopy, inmunihistochemistry and electron microscopy that confirm the diagnosis of this LCH. The Clinical course and the response to the treatment are variable. In this article we report 3 cases diagnosed in the "Materno Infantil Institute" and "National Cancer Institute " in Bogota and make a review of literature.

KEY WORDS: Langerhans cell histiocytosis, Female genital tract, Diabetes Insipid.

\section{Introducción}

La Histiocitosis de células de Langerhans (HCL), denominada anteriormente en la literatura médica, como Histiocitosis de células $\mathrm{X}$, es una entidad poco frecuente, que incluye una variedad de enfermedades, que tienen en común, la proliferación clonal anómala de una línea celular, que desde el punto de vista morfológico, histoquímico e inmunofenotípico es similar a las células de Langerhans (1-2). Es de anotar que el compromiso del

1 Residente I. Departamento de Ginecología y Obstetricia, Facultad de Medicina Universidad Nacional. Instituto Materno Infantil.

2 Profesora Asistente. Departamento de Patología, Facultad de Medicina. Universidad Nacional. Instituto Materno Infantil.

3 Profesora Asociada. Departamento de Patología, Facultad de Medicina. Universidad Nacional. Instituto Nacional de Cancerologia.

4 Profesor Asistente. Departamento de Patología, Facultad de Medicina. Universidad Nacional. Instituto Nacional de Cancerologia.

5 Profesor Asociado. Departamento de Ginecología y Obstetricia, Facultad de Medicina. Universidad Nacional. Instituto Materno Infantil.

6 Profesor Asociado. Departamento de Ginecología y Obstetricia, Facultad de Medicina. Universidad Nacional. Instituto Materno Infantil. tracto genital femenino (TGF) por la HCL es muy raro, vino a ser descrito por primera vez en el año de 1939 por Andrews, desde entonces se han informado casos individuales y series pequeñas. El compromiso a este nivel es variado, puede ser solitsrio vulvar, vaginal y/o cervical, o, concomitante con otras lesiones sistemicas, óseas o con diabetes insípida, los cuales pueden preceder por meses o aun años al compromiso genital. Recientemente en el Instituto Materno Infantil (IMI) y el Instituto Nacional de Cancerología (INC) de Bogotá fueron diagnosticados tres casos nuevos, los cuales son la base de nuestra presentación.

\section{Presentación de los casos}

\section{Caso No. 1}

Mujer de 34 años de edad G1 P1 A0, quien ingresó al servicio de sépticas del IMI en julio de 1998 por presentar lesiones nodulares, eritematosas, redondeadas y ulceradas localizadas en la vulva, las cuales tenían tendencia a confluir y se extendían hasta el introito vaginal (Foto No1). El estudio inicial de la secreción de estas lesiones revelo la presencia de diplococos gram negativos 
intracelulares y extracelulares, con estos hallazgos y el aspecto clínico de las lesiones se sospechó una Enfermedad de Transmisión Sexual (ETS), Chancroide Vs Herpes genital sobreinfectado, se le inició tratamiento antibiótico. Ante la falta de mejoría y la aparición de nuevas lesiones en la vulva y la cavidad oral (Foto No. 2), fue valorada por el servicio de Dermatología del HSJD quienes plantearon como diagnósticos iniciales una enfermedad metastásica, granuloma inguinal, condiloma lata, pénfigo vegetante y amibiasis cutánea, le fue realizada una biopsia cuyo informe de anatomopatológico fue $\mathrm{HCL}$ en el tracto genital inferior (vulva). Como antecedentes tenia un parto hacia 13 años y un solo compañero sexual. Había sido vista en el Hospital San Juan de Dios (HSJD) en la consulta de endocrinología en Junio de 1997 por un cuadro de 4 años de evolución de oligoamenorrea asociada a secreción escasa por el pezón, oleadas de calor, piel seca y disminución del vello púbico y axilar, en los últimos meses dicha sintomatología se

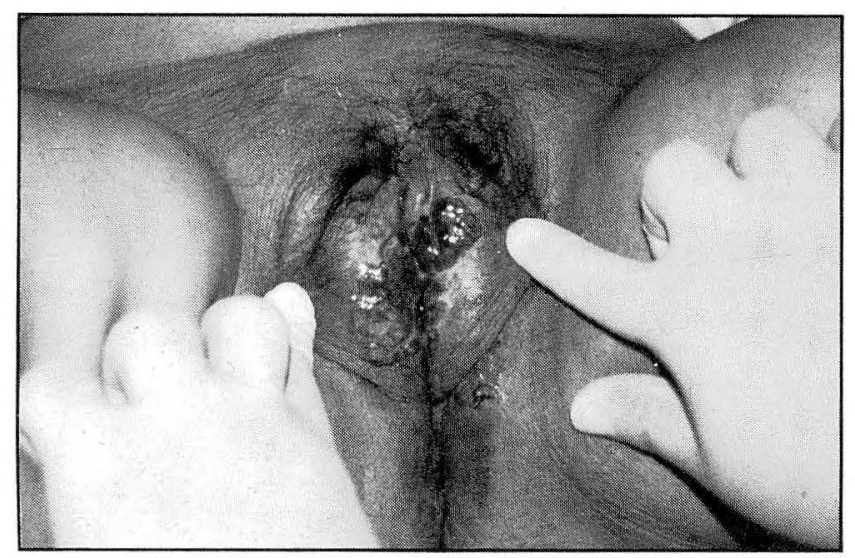

Foto 0020101

\section{LESIONES ULCERADAS IRREGUALES DE BORDES Y FONDO ERITEMATOSO CONFLUENTES LOCALIZADAS A NIVEL DEL INTROITO VAGINAL (Caso No 1)}

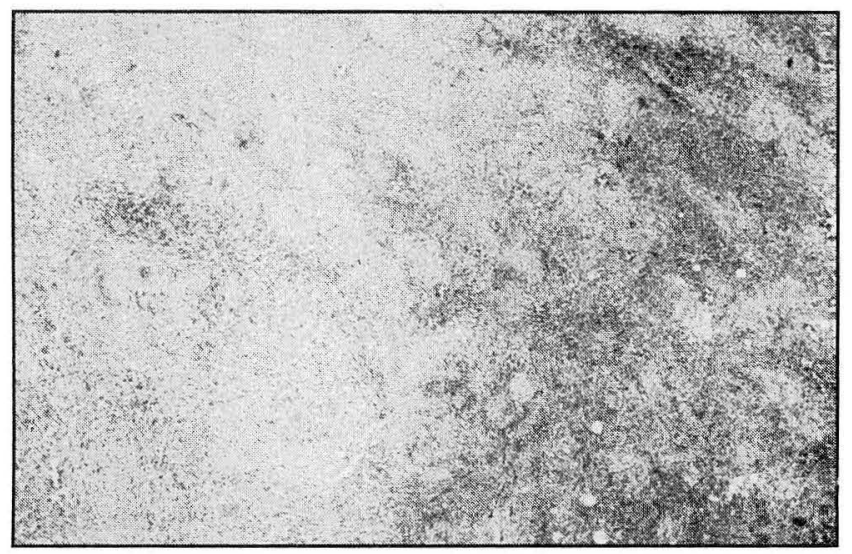

Foto $0020 \mathrm{i} 03$

CÉLULAS DE LANGERHANS BIEN DIFERENCIADAS DISPUESTAS DANDO UN PATRÓN SINCITIAL

(Caso No 1) (H\&E - $10 \mathrm{X})$. había acompañado de polidipsia y poliuria. En ese entonces le fue documentado una hiperprolactinemia y un hipotiroidismo junto a niveles bajos de hormonas gonadotropas, por lo cual, se le realizo TAC cerebral, que mostró una masa hipercaptante hipotalámica quiasmática y una Resonancia magnética (RM) con contraste que informó una lesión neoplásica del quiasma óptico con dimensiones máximas de $20 \times 18 \mathrm{~mm}$, muy probablemente de origen glial: Glioma del quiasma óptico. Fue llevada a cirugía en julio de 1997 para realizar biopsia obteniéndose escaso material; el estudio histologico de este material revelo una gliosis reactiva. Durante el postoperatorio presentó alteración hidroelectrolítica, asociada a gasto urinario elevado, que fue interpretado como secundario a una diabetes insípida, o a sobredosificación de esteroides. Por persistencia de la sintomatología endocrinológica se le dio suplencia hormonal (Bromocriptina y Provera), con mejoría parcial.

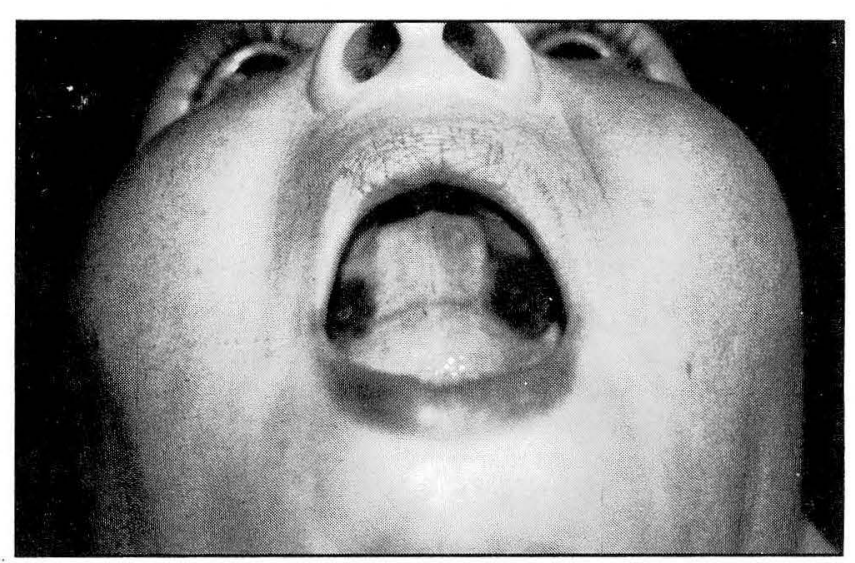

Foto $0020 \mathrm{i02}$

\section{PLACAS ERITEMATOSAS LOCALIZADAS A NIVEL DEL PALADAR DURO (Caso No 1)}

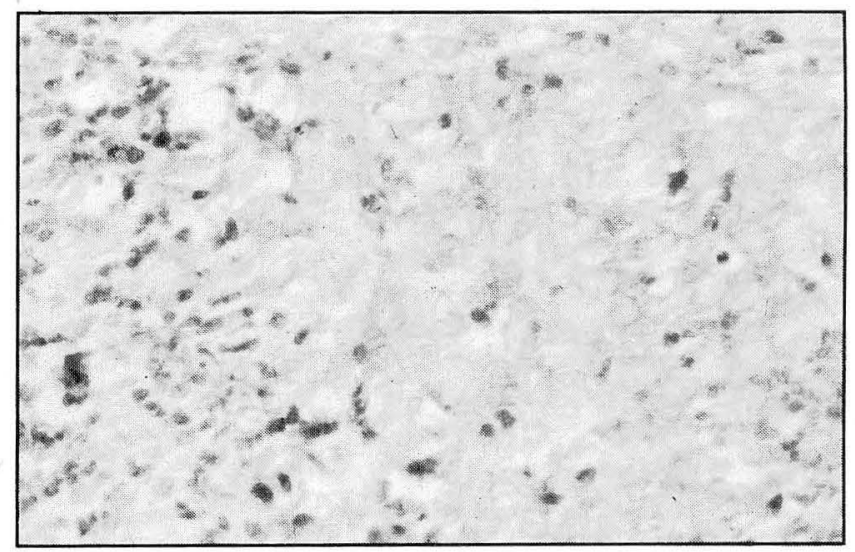

Foto 0020i04

EVIDENCIA DE POSITIVIDAD EN LAS CÉLULAS TUMORALES CON EL ANTICUERPO CD1A

(Caso No 1) 


\section{Caso No. 2}

Mujer de 55 años de edad vista en el INC desde 1983 por una lesión lítica a nivel supra-acetabular derecho la cual fue diagnosticada como Histiocitosis X. A su vez la paciente presentaba un cuadro de varios años de evolución de polidipsia y poliuria, documentado en los exámenes paraclínicos por lo cual además se le realizó el diagnóstico de Diabetes insípida asociada a Histiocitosis $X$ y se le inicio manejo con tiazidas. Cinco meses después, en un control radiológico, se evidencio compromiso poliostótico, por la extensión del compromiso se inicio manejo con quimioterapia (Vinblastina + Ciclofosfamida). Posteriormente, la paciente presentó periodos de remisión y recaída. Además de la diabetes insípida, no se evidencio otra alteración de las hormonas hipofisiarias. Por persistencia del compromiso óseo, la paciente se sometió nuevamente a quimioterapia (Ciclofosfamida, Vinblastina, Prednisona), con remisión parcial del proceso, y mejoría sintomática sin embargo las lesiones fueron refractaria al tratamiento por lo que se le dio un nuevo régimen quimioterapéutico, adicionando Adriamicina, a pesar de lo cual no se vio remisión total de la entidad. Después de nueve años, la paciente presentó resolución de la sintomatología ósea inicial, no obstante, aparecieron unas lesiones dérmicas de carácter papular en el abdomen y nuevas lesiones óseas bilaterales localizadas en el trocanter femoral. El estudio histopatológico informó compromiso por Histiocitosis $\mathrm{X}$. Recientemente se documento control del la Diabetes ínsipida y un hipotiroidismo subclínico (Elevación de la $\mathrm{TSH}$, con T4 normal). Fue remitida a Ginecología para valoración por menopausia y se le encontró en el examen físico 2 lesiones ulcerativas cerca de la horquilla vulvar, las cuales tenían 8 meses de evolución. El estudio anatomopatológico de estas fue informado como compromiso de la vulva por una HCL.

\section{Caso No 3}

Mujer de 36 años de edad quien fue remitida al INC en septiembre de 1997 con diagnostico de Carcinoma escamocelular infiltrante del cervix. Clínicamente presentaba un cuadro de 6 meses de evolución consistente en dolor pélvico y sangrado inter-menstrual. Antecedentes, menarquía a los 13 años, ciclos de $30 \times 4$, FUR agosto de 1997, G2 P2 A0, un solo compañero sexual, planificación familiar DIU durante 5 años, luego se realizó pomeroy. Al examen ginecológico se evidencio cuello central, irregular y duro con múltiples ulceraciones, una de ellas periorificial, se realizó diagnostico inicial de Carcinoma de cervix estado IB. En los exámenes prequirúrgicos de extensión se encontró además un nódulo pulmonar en el lóbulo medio que se diagnostico por biopsia como granuloma micótico. Le realizaron histerectomía total ampliada con linfadenectomía cuyo estudio histopatológico reporto una HCL con compromiso del cervix y la vagina anterior. Dos meses después por compromiso residual de la cúpula vaginal le realizan braquiterapia de baja tasa. En junio de 1998 clínicamente encuentran una lesión ulcerada de $0.5 \mathrm{~cm}$ en pared lateral de vulva. La paciente hasta el momento no ha regresado a control.

\section{Discusión}

Las células de Langerhans (CL) son una población de células que tienen prolongaciones citoplasmáticas dendríticas y grandes cantidades de antígenos HLA clase II sobre su superficie (3). Esta línea celular, que se origina en la medula ósea, se encuentra distribuida por todo el cuerpo, especialmente en órganos linfoides y en tejidos con exposición directa al medio externo como la epidermis y las mucosas como la cavidad oral, el tracto gastrointestinal y el tracto genital femenino $(3,4)$. Se ha postulado que estas células hacen parte del sistema macrofagocítico alojado en estas mucosas (4). Estas células están involucradas en fenómenos inmunológicos, específicamente, aquellos relacionados con la presentación (3-4) y el procesamiento periférico de antígenos, por tanto son esenciales para la integridad del sistema inmune (5).

Con la coloración de rutina (H\&E) las CL son de aspecto dendrítico, de núcleos irregulares usualmente ovoides, con plicas o hendiduras prominentes que dan el aspecto característico de "grano de café", tienen un nucléolo poco prominente, su citoplasma es abundante y acidófilo, y presentan mitosis escasas o ausentes $(1,6)$. Aunque este aspecto es característico solo permite realizar un diagnóstico presuntivo, para ser confirmado se requiere realizar estudios de inmunohistoquímica y/o microscopía electrónica. Desde el punto de vista inmunohistoquímico las CL reaccionan con los anticuerpos para la adenosín trifosfatasa, la glicoproteína timocítica CD1, la proteína S 100 y los antígenos HLADR del complejo mayor de histocompatibilidad clase II $(2,4)$. La positividad en la reacción con la proteína S 100 por convención es aceptada como una característica útil en la diferenciación entre Histiocitosis X y varias proliferaciones histiocíticas del tipo no Histiocitosis X, como el Xantogranuloma juvenil y el Reticulohistiocitoma (8). El estudio de ultraestructura de estas células se caracteriza por la presencia de unos gránulos intracitoplasmáticos conocidos como gránulos de Birbeck $(2,4)$, dichos gránulos, tienen la forma de una varilla o una raqueta de 200 a $400 \mathrm{~nm}$ de longitud, y $33 \mathrm{~nm}$ de grosor y su apariencia

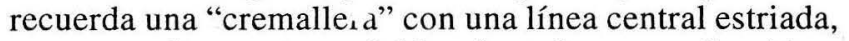
y una envoltura externa doble; sin embargo, su función y origen aún no son conocidos (7).

La etiología de la HCL aún no esta establecida; sin embargo, se acepta que es la manifestación de una perturbación inmunológica no determinada, relacionada con la manera en que los macrófagos procesan los antígenos y los complejos antígeno-anticuerpo "asociados a superficie". Esta entidad tiende a comprometer aquellos sitios en los que usualmente las CL están presentes, o aquellos lugares que poseen una importante población residente de células del sistema mononuclear fagocítico. (4)

Recientemente algunos estudios, han dado nuevas luces sobre la etiología y la patogénesis de la HCL. Se han implicado a los virus, como iniciadores de la enfermedad; no obstante, no se han encontrado genomas virales en las lesiones. Aunque se sabe que existe una perturbación inmunológica, esto parece ser mas una consecuencia que la causa de la entidad. Los estudios 
moleculares han demostrado que la HCL, es una enfermedad monoclonal histiocítica para $\mathrm{CD} 1 \mathrm{a}$, mas que un desorden policlonal (9). Así, el hallazgo de que todas las formas de HCL son clónales, ha permitido sugerir que esta enfermedad es de carácter neoplásico, con un comportamiento biológico y un cuadro clínico muy variables, esto se ve apoyado por la teoría que plantea la existencia de una mutación somática en una célula progenitora. Desde este punto de vista, la HCL proviene de una mutación genética adquirida que da lugar a la expresión clonal de células de Langerhans y sus precursores en la médula ósea; en contra de esta hipótesis se postula el hecho que la HCL no tiene una expresión de tipo familiar (9). En esta entidad también se han visto anormalidades citogenéticas como disrupciones cromosómicas y se ha descrito que el clon celular proliferante puede expresar niveles elevados de factor de necrosis tumoral, interferón gama, factor estimulante del crecimiento de colonias granulocito-macrófago, interleucina 1 y factor inhibidor de leucemia (md6). La causa de estos fenómenos es desconocida, pero al parecer existen cambios en las secuencias del DNA en los genes promotores de estas citoquinas que pueden alterar sus expresiones (11).

La HCL es una entidad que se presenta habitualmente en niños, adolescentes, y adultos jóvenes, y compromete múltiples órganos y tejidos, caracterizándose por la aparición de múltiples lesiones óseas en prácticamente cualquier localización (12), siendo las mas frecuentes el cráneo, las costillas y los fémures (2). En una tercera parte de los pacientes aparece diabetes insípida transitoria o permanente, debida al compromiso granulomatoso del hipotálamo(12-13), también se pueden afectar la piel, la región vulvar, las encías, el pulmón y el timo (12).

El término Histiocitosis $\mathrm{X}$ incluye el síndrome de Letterer Siwe (SLS), la enfermedad de Hand-SchüllerChristian (EHSC) y el Granuloma eosinófilo (GE). Se cree que estas tres entidades representan distintos patrones clínico patológicos del mismo trastorno básico, difiriendo en lo que se refiere a la extensión del compromiso orgánico y al pronóstico(1-2). La primera, es una proliferación generalizada, progresiva, aguda ó subaguda, que se ve clásicamente en lactantes y niños menores de tres años(2), siendo entonces una forma de enfermedad con compromiso agudo y sistémico (4). La evolución es variable, dependiendo de la edad de inicio y la extensión del compromiso, con empeoramiento del pronóstico en niños menores de seis meses (2). El GE puede ser unifocal, de curso benigno, predomina en varones, con compromiso principalmente óseo. La combinación de defectos óseos del cráneo con diabetes insípida y exoftalmos se conoce como la triada de Hand-Schüller-Christian, sin embargo, solo una pequeña parte de los pacientes con enfermedad multifocal presentan la triada completa. $(1,2)$. La EHSC es entonces la forma crónica y progresiva de esta entidad (4).

Dentro de este gran espectro de la enfermedad, se ha informado el compromiso del sistema nervioso central (SNC), siendo mas frecuente el compromiso del eje hipotálamo-hipofisiario, manifestado como Diabetes insípida seguido por otras endocrinopatías y disfunción hipotalámica $(14,15)$. También pueden verse comprometidas otras partes del SNC, como las meninges, el cerebelo y los plexos coroideos, brindando una amplia gama de signos y síntomas(14). Se ha descrito el panhipopituitarismo, incluyendo el hipogonadismo hipogonadotrópico como consecuencia del compromiso infiltrativo de la hipófisis o del hipotálamo, a nivel dural o capsular, con compresión de la hipófisis anterior. Se postula que la Diabetes insípida y la deficiencia de la hormona del crecimiento, se deben al compromiso del núcleo supraóptico del Hipotálamo, lo que también explica los casos de amenorrea secundaria producida por una alteración de la secreción de GnRH y, en consecuencia, de las gonadortofinas (15-17), tal como ocurrió en dos de los casos informados. También se han descrito casos acompañados de hiperprolactinemia (18), como en el primer caso y de Hipotiroidismo primario, como en el segundo caso, cuya etiología no esta establecida y aunque es exótico podría estar acurriendo por una infiltración granulomatosa de la glándula tiroides por la HCL (1718). La HCL, así como los granulomas y la Tuberculosis, pueden causar masas paraselares, estas condiciones usualmente se presentan como diabetes insípida, con o sin disfunción de la hipófisis anterior, e hiperprolactinemia; la disfunción gonadal puede ser un signo periférico temprano en adultos (19). Aunque la biopsia de la primera paciente no fue representativa, el cuadro clínico en general es sugestivo de la existencia de compromiso del SNC por la HCL.

El compromiso del tracto genital femenino por la HCL es bastante raro (4,16,21-23). Hasta el año de 1991, se habían reportado en la literatura 43 casos $(4,21)$. En una búsqueda realizada en la base de datos del Medline desde el año de 1992 hasta la fecha, se encontraron 2 casos nuevos (22-23). En la presente revisión estamos informando 3 casos nuevos.

El compromiso genital de la HCL, simula varias entidades neoplásicas y no neoplásicas; clínicamente puede presentarse como lesiones eritematosas y pruriginosas que simulan un eccema o una dermatitis seborréica. (4). La presentación papular puede simular un chancroide, un linfogranuloma venéreo o un granuloma inguinal (4), entidades de diagnóstico diferencial que se plantearon en el caso No 1. Las úlceras induradas aisladas deben diferenciarse de los chancros sifilíticos, la TBC, la enfermedad de Crohn y el carcinoma escamocelular como en el último caso $(4,21)$. También puede presentarse como lesiones ulcerativas destructivas de vulva y vagina (24). La presentación como una lesión vesicular-ulcerada, dolorosa puede ser confundida con herpes genital (diagnostico diferencial planteado en el caso No 1), eritema multiforme y síndrome de Bechet. Cuando las lesiones se manifiestan como múltiples masas, el diagnóstico diferencial debe hacerse con melanomas malignos y sarcomas $(4,21)$.

Dado que el diagnóstico clínico es difícil pues no se encuentra una lesión típica, el procedimiento inicial a realizar es el estudio histopatológico del tejido(4), acompañado del análisis inmunohistoquímico (21-22), específicamente la determinación de la proteína S-100 y el CD1a $(4,7,22)$. En el estudio histológico, la HCL se 
ve como una lesión de carácter inflamatorio crónico y necrotizante, con la presencia de las células antes mencionadas (6). La lesión típica de la HCL, está formada por colecciones de células de Langerhans y macrófagos, acompañados de linfocitos $\mathrm{T}$, con un número variable de histiocitos y eosinófilos. La clave en el diagnóstico diferencial de la HCL esta en la presencia de células de Langerhans bien diferenciadas con núcleos vesiculares plegados, con múltiples identaciones, que tienden a agregarse en "grupo de láminas" dando un patrón sicitial. $(1,4,24)$ (Foto No 3). Para el diagnóstico definitivo, se requieren estudios especiales como la microscopía electrónica para determinar la presencia de los gránulos de Birbeck o la determinación inmunohistoquimica de la expresión del antígeno de superficie CD1a (Foto No 4) $(7,9,25)$. El hallazgo de los gránulos de Birbeck intracitoplasmáticos distingue a las células de Langerhans patológicas. (7).

En 1987, el "Writing group of the Histiocyte Society", hizo algunas recomendaciones a seguir con animo de mejorar la especificidad del diagnostico de la HCL. Estas recomendaciones se esbozan en la tabla a continuación (25).

\section{Tabla 1}

1. Diagnóstico presuntivo: Microscopía de luz.

2. Diagnóstico probable: Microscopía de luz acompañado de dos o más coloraciones positivas para: ATP-asa.

S-100.

Alfa D-manosidasa. Lecitina Peanut

3. Diagnóstico definitivo: Microscopía de luz y de Mostración de los gránulos de Birbeck en las células de la lesión por microscopía electrónica y/o coloración positiva para CD1a en la célula de la lesión.

El compromiso del TGF por la HCL es más frecuente localizado en la vulva, la vagina y el cervix, siendo la vulva vista hasta en un $87 \%$ de los casos (4), de los cuales en el $64.5 \%$ la lesión vulvar es la única manifestación de la enfermedad. Con un $32 \%$ de los casos le sigue en frecuencia de presentación las lesiones genitales múltiples. Las lesiones cervicales y vaginales aisladas son muy raras (4 y $2 \%$ respectivamente) y otras localizaciones como el ovario y el endometrio son infrecuentes (4).

Con base en la presentación clínica inicial y la extensión anatómica de la misma el compromiso del TGF por la HCL se ha dividido en cuatro grupos $(4,7)$.

Grupo 1. HCL con compromiso aislado del TGF. El cual incluye el $16.7 \%$ de los pacientes con HCL del tracto genital. La edad promedio de inicio de la enfermedad es de 44 años, con un rango entre los 24 y 85 años. Las pacientes se presentan tanto con úlceras vulvares, como con pápulas vulvares que posteriormente se ulceran. En este grupo de pacientes no se documenta compromiso multiorgánico o sistémico, por fuera del TGF. La dura- ción de la enfermedad activa, varia entre 0.5 y 9 años con un promedio de 3.2 años $(4,22)$.

Grupo 2. HCL del TGF, con compromiso multiorgánico secundario. El $16.7 \%$ de las pacientes con HCL del TGF, desarrolló posteriormente compromiso multiorgánico por la enfermedad, manifestado como diabetes insípida, infiltrados pulmonares y lesiones óseas. En este grupo la edad promedio de inicio de la enfermedad fue de 30 años con un rango entre los 22 y los 38 años, variando la duración de la enfermedad activa entre 0.5 y 9.5 años. Es de anotar que en 1990 se reportó el caso de una niña de 2.5 años de edad $(21,25)$. El tiempo de aparición del compromiso sistémico después de la presentación de la lesión genital varió entre 5 meses y 6 años con un promedio de 2.8 años.

Grupo 3. HCL cutánea o de cavidad oral con compromiso secundario del TGF. Este grupo incluye el 19\% de las pacientes con HCL del tracto genital inferior. El $75 \%$ de estas, desarrolló un compromiso aislado del tracto genital inferior y el restante, hizo compromiso sistémico. La edad promedio de inicio de la enfermedad es de 21 años con un rango variable entre los 8 y los 44 años. La duración de la enfermedad activa, varió entre los 3 meses, y los 18 años con un promedio de 6 años. Las lesiones orales o cutáneas precedieron a las lesiones genitales y multiorgánicas entre 6 meses y 8 años con un promedio de 5 años.

Grupo 4. Diabetes insípida con compromiso secundario por HCL del TGF y multiorgánico. Comprende el $45 \%$ de los casos. La edad promedio entre la instauración de la diabetes insípida y el compromiso genital varió entre 8 meses y 20 años, con un promedio de 8 años. La duración de la enfermedad activa, varió entre los 3 y los 22 años, con un promedio de 9.4 años

El compromiso del TGF por la HCL puede ocurrir a cualquier edad, aunque es más frecuente en adultos jóvenes. Aparentemente no hay correlación entre la histología y la evolución de las lesiones genitales, tampoco existe correlación entre la presentación clínica y/o la extensión del compromiso y la evolución de las lesiones genitales. En estas pacientes se ha visto tanto la regresión completa de la entidad, como la persistencia parcial o total de las lesiones y recurrencias (4).

El tratamiento para la HCL del TGF, aun no ha sido bien establecido, y varia de acuerdo a cada paciente. Se han descrito tratamientos con cirugía, radioterapia, corticoides tópicos y quimioterapia, o combinaciones entre ellos y aun la simple observación. Hasta el momento no se ha encontrado una modalidad terapéutica mejor que otra (4).

El tratamiento quirúrgico ha mostrado resultados favorables; sin embargo se han reportados casos de recurrencia. Las lesiones genitales por HCL suelen responder a radioterapia; no obstante, algunas pueden llegar a ser refractarias al tratamiento, como pueden recurrir. Sumado al hecho que la piel de la vulva puede presentar efectos secundarios a la radiación, que pueden llevar al abandono del tratamiento, o la falla del mismo (4).

El papel de la quimioterapia en le manejo de la HCL con compromiso genital, no ha sido bien definido, debido al numero reducido de pacientes que se han tratado. 
Hasta el momento el consenso es utilizarla en pacientes con enfermedad multifocal, o en aquellos casos en los que las lesiones han sido refractarias a manejos más conservadores $(4,21)$. Se han reportado remisiones tota- les o parciales con Vinblastina y el Etopósido, este ultimo con menor toxicidad y mejor tolerancia (4). Igualmente se han visto buenos resultados con corticoides tópicos.

\section{BIBLIOGRAFIA}

1. Rosai J. Surgical Pathology. 8a Ed. Ed Mosby co. 1996; 1695.

2. Cottran R., Kumar V., Robbinns S. Patologic basis of the disease. 5 Ed. Interamerricana. 1994; 666.

3. Robbins S., Kurmar V. Patología humana.4a Ed.Interameicana. 1990; 135.

4. Axiotis C., Merino M., Duray P. Langerhans cell Histiocytosis of the female genital tract. Cancer. 1991; 67: 1650-1660.

5. Munn S.,Chu a. Langerhans cell Histiocytosis of the skin. . Hematol. Oncol .Clin. North. Am. 1998; 12(2): 269-86.

6. Gompell C., Silverberg S. Pathology in Gynecology and Obstetrics. 4 Ed. Philadelphia: J.B.Lippincott. 1994:

7. Schmitz L., Favara B.G. Nosology and pathology of Langerhans cell Histiocytosis. Hematol. Oncol. Clin North. 1998; 12(2): 221-46.

8. Tomaszewski MM. Lupton GP. Unusual expresion of S-100 protein in Histiocytic neoplasms. J. Cutan. Pathol. 1998; 25(3): 129-35.

9. Cheryl W., McClain K. An update on Clonality, citokines and viral etiology in Langerhans cell Histiocytosis. Hematol. Oncol .Clin. North. Am. 1998; 12(2): 407-16.

10. Betts DR. Leinbundgut KE., Feldges A., Pluss HJ., Niggli FK Cytogenetic abnormalities in Langerhans cell Histiocytosis. Br.J.Cancer. 1998; 77(4): 552-5.

11. Wu WS., McClain KL. DNA polymorphisms and mutations of the tumor necrosis factor- alpha (TNF-alpha) promoter in Langerhans cell Histiocytosis (LCH). J. Interferon Cytokine Res. 1997; 17(10): 631-5.

12. Wilson J., Braunwald E., Isselbacher K., et al. Harrison. Principios de Medicina Interna. 12 Ed.Mexico: Interamericana. 1991; 421-422.

13. Kurman RJ. Blaustein's Pathology of the Female genital tract. 3Ed Ed Springer Verlag. 1987:

14. Grois N., Favara B., Mostbeck G., Prayer D. Central nervous system disease in Langerhans cell Histiocytosis. Hematol-oncol Clin. North Am. 1998;12(2): 287-305.

15. Kasa-Vubu J., Kelch RP. Prococious and delayed Puberty : Diagnosis and treatment. En De GrootLT., Besser M., Burger H., Jameson JL.,
Rubensbin AH (Eds). Endocrinology. 3 Ed. Philadelphia: WB Saunders Co. 1995; 2: 1153.

16. Issa P., Salem P., Brihi E., Azoury R. Eosinophilic granuloma with involvement of the female genitalia. Am. J. Obstet. Gynecol. 137: 608-12.

17. Rami B.,Schneider U., Wandl Vergesslich K., et al. Primary hipothyroidism, central diabetes insipidus and growth hormone deficiency in multisistem Langerhans cell histiocytosis.: a case report. Acta. Paediatr. 1998; 87(1): 112-4.

18. Panza N., Merola B., Colao A., Iodice G., et al. Langerhans cell Histiocytosis, diabetes insipidus, hiperprolactinemia and empty sella: a four fold association. Report of two cases. . Endocrinol Invest. 1996, 19(1): 43-7.

19. Melmed S. Tumor mass effects of lesions in the hypothalamus amd the pituitary. En De GrootLT., Besser M., Burger H., Jameson JL., Rubensbin AH (Eds). Endocrinology. 3 Ed. Philadelphia: WB Saunders Co. 1995; 1: 458.

20. Witte RJ., Mark LP., Daniels DL., Haughton VM. Radiographic evaluation of the pituitary and anterior hypotalamus. En De GrootLT., Besser M., Burger H., Jameson JL., Rubensbin AH (Eds). Endocrinology. 3 Ed. Philadelphia: WB Saunders Co. 1995; 1: 467.

21. Otis C., Fischer R., Johnson N., Keller J., Powell J. Histiocytosis X of the Vulva: A case report and review of the literature. Obstet Gynecol; 75 (3): $555-8$

22. Stentella P., Cipriano L., Covello R., et al.Langerhans cell Hisiocytosis of the vulva and the cervix in a 19 year old woman. Gynecol. Obstet. Invest. 1997; 44(1): 67-9.

23. Voelklein K., Horny H. Prymary Langerhans Cell Histiocytosis of the vulva. Gynecol. Obstet. Invest. 1993; 36(3): 189-90.

24. Kaufman R. Enfermedades benignas de Vulva y Vagina. 4Ed. Mosby Doyma Libros S.A. 1996:

25. Aricó M. Maarten E. Cliniical aspects of langerhans cell Histiocytosis. Hematol. Oncol. Clin .North. Am. 1998; 12(2): 247-58. 